ISSN 2661-2666( Online) International Scientific Journal “Monte" DOI : $\underline{10.33807 / m o n t e .1 .201904160}$

ISSN 2661-264X (Print)

\title{
FUNDAMENTAL AND TECHNICAL ANALYSIS OF THE STOCK PRICE
}

\author{
Denis Spahija PhD. Candidate, University of Gjakova "Femi Agani" \\ Prof dr.Seadin Xhaferi, University of Tetova
}

\begin{abstract}
Trading with stocks in developed market conditions for some is fun, for others it is a way to preserve the real value of the asset, while for the most is a challenge to gain bigger profits quickly and easily.

Dreams on stock market alchemy rely on the development and upgrading of special systems whose ultimate goal is to uncover stock price secrets and their changes. What are the chances of this happening?

Chances are minimal, according to experiences from the world's leading stock exchanges in the past. The stock market complexity, the number and unpredictability of factors affecting stock prices and unexpected changes or stability do not give much hope to those who know what's going to happen in the future. In such endeavors there are equal opportunities for both stock exchange experts and full-time amateurs.

For all this, if the stock market cannot be defeated or deceived, then it is better to join it. So this means: to create a diversified portfolio of securities that provides a safe income, slightly higher than annual inflation, minimizing the risk.
\end{abstract}

Key words: stock market, stock price, financial market, financial forecasts.

\section{INTRODUCTION}

In countries with a developed market and a major stock market tradition, securities trading is an attractive activity for both stock exchange experts and the uninformed investors. In short, a number of small and large investors try to win the market by predicting future events. Based on the expected price changes, the sale or purchase of stock materials is done. For this reason, there are various methods in use: such as analysis of general economic development indicators or the application of different models. So in both cases the goal is the same: sell when the price is higher - buy when the prices are lower.

Fundamental funders are exploring macroeconomic aggregates, and based on the current state of affairs and expected changes, future price outlines are drawn. Such an approach is based on real economic categories and rational completion elements. Technical analysis becomes more affirmative in a broader audience. At first glance the reasons seem to be very convincing: on the basis of the price movement of securities in the past, the position for future flows is also formulated. In such an approach, there must be no persistence in the scientific bases of the methods that apply but in reality their applicability in practice. Thus, various forms of statistical analysis developed by stock exchange experts. The question is whether or not the market can be obtained using fundamental or technical analysis; ie. Was the stock price alchemy detected? 


\section{METHODS USED FOR IDENTIFYING AND PROVIDING THE FUTURE OF MOVEMENT PRICES}

Following the most explicit stock conditions and their main characteristics, as well as the main stock indexes, the following will be keen to the main techniques and methods for defining and forecasting the future movement of their values.

2. 1. The main methods for determining the value of shares

Each action may or may not have a nominal value. The nominal value represents the "initially planned and initially estimated value" by which the action is first transmitted to the market that is recorded in the share during the initial issue. There are two basic sets of valuation methods:

1) Balance method;

2) Method of deduction.

2. 1. 1. Balance method for determining the value of shares

\section{1) Accounting value of the share}

One of the main methods of valuation balance is the determination of its carrying amount, which is taken as the ratio of the net value of the enterprise and the number of ordinary shares issued. The basis for determining the carrying amount is the balance sheet of the company, while the net value represents the difference between assets and liabilities. The carrying amount actually indicates the stable resources of the allocated funds for individual stocks. The main constraint on the carrying amount of the share is ,that it is determined on the basis of the loan, which is based on the results achieved in the past, during which the determination of these values is conditioned by the respect and application of numerous accounting principles".

On the contrary, the market price also includes the expected results, and will usually be higher than the book price. If the company does not produce good results, the market price may be lower than that of accounting, so the carrying amount can not represent a lower reliable limit below which the market price of the share may not fall.

\section{2) Liquid share value}

A much more credible measure for determining the lower price limit of the stock market is the amount of liquidation of the company for ordinary shares. Where the value of liquidation represents a profit from the sale of the company's assets, which is reduced by debt repayment. Thus, here is supposed termination of business operations and the sale (liquidation) of its assets and repayment of debts, therefore the liquidation value is lower than the carrying amount. Liquidation value is also an important indicator in taking the company. That is, if the market value of the stock price depreciates below its liquidation value, the company will become an attractive target to take, no matter how its other performance is.

\section{3) Reproductive value (replacement costs)}

Another important method of balance for determining the value of the stake is the replacement cost of the company or the costs necessary to create approximately the same company. The market value of a company should not be much higher than the value of its reproduction, otherwise the competitors would be motivated to create the same company and the increase in competition and the appearance of similar companies in the branch would result in lowering the market value and approximating it with replacement costs. 
Within this concept, the indicator Tobin $\mathrm{q}$ is used, which represents the relationship between the company's market value and the value of its reproduction, that is, the replacement cost.

\section{1. 2. The discounting methods for determining the value of shares}

Although the financial statements provide a significant basis for determining the value of a firm, they are based on historical values and as the company continuously operates, it is necessary to take into account the expected future cash flows that it will realize. Therefore, discounting methods of stock valorisation are used, which are intended to determine the intrinsic value (intrinsic value).

The domestic stock value is compared with the current market price to determine whether an action is exaggerated or underestimated. Over-appreciated items are those whose current market price is higher than the domestic ones and they should be sold, and then be sold undervalued, the current price of which is lower than the domestic value. Previously, we mentioned that return on investment includes realized capital gains and cash dividends. Then we can determine the expected yield in the Expected HPR, according to the formula:

Where:

$$
\text { ExpectedHPR }=\mathbf{E}(\mathbf{r})=\frac{\mathbf{E}\left(\mathbf{D}_{\mathbf{1}}\right)+\left(\mathbf{E}\left(\mathbf{E P}_{\mathbf{1}}\right)-\mathbf{P}_{\mathbf{1}}\right)}{\mathbf{P}_{\mathbf{0}}}
$$

E (r) - Expected future value of the action;

$\mathbf{E}\left(\mathbf{D}_{1}\right)$ - Dividing the pending cash;

$\mathbf{E}\left(\mathbf{P}_{\mathbf{1}}\right)$ - The expected share price at the end of the period;

$\mathbf{P}_{\mathbf{0}}$ - Share price at the beginning of the period.

So the expected return on investment is actually the amount of expected dividend yield - $E\left(D_{1}\right) /$ $\mathrm{P}_{0}$ and expected return on capital gain - $\left(\mathrm{E}\left(\mathrm{P}_{1}\right)-\mathrm{P}_{0}\right) / \mathrm{P}_{0}$. However, in order to determine whether an action is interesting to the investor or not, or if it is exaggerated or underestimated, it is necessary to compare the expected rate of return with the required rate of return. To determine the required level of yield, we have three main types of discount methods available:

1. The capitalization method of profit;

2. Methods of discounting dividends;

3. Money discounting method.

1) The profit capitalization method starts with Capital Asset Pricing Model(CAPM) model, which links the required yield rate of a certain value paper with its risk (which determines $\beta$ ).

According to the CAPM model, the ratio between the required yield and $\beta$ is as follows:

$$
E(r D)=r f+\beta D(E(r M)-r f)
$$

Where:

$$
\begin{aligned}
& E(r D) \text { - the required level of yield; } \\
& r f \text {-free yield rate; } \\
& E(r M) \text { - Expected market rate; } \\
& \beta D \text { - beta (risk) of a given paper. }
\end{aligned}
$$

In the text below, we will mark the required return rate with $\mathrm{k}$. If the expected return is higher than the required return, the action will be underestimated and the investor will want to have more such shares in his portfolio. On the other hand, if the expected return is lower than required, the action is overestimated and the investor will not be interested in keeping it.

Another way to determine the required rate of return is based on comparing the internal share value with the current market price. Intrinsic value - internal (I0) represents the present value of the expected future 
cash flows of the companies, discounted at the required return rate $(\mathrm{k})$. Shares will be underestimated and represent a good investment if the domestic value is higher than the stock market price. On the other hand, if the domestic value is lower than the market price, the shares will be overestimated. The formula for determining the internal value is:

Where:

$$
\mathbf{I}_{\mathbf{0}}=\frac{\mathbf{E}\left(\mathbf{D}_{\mathbf{1}}\right)+\mathbf{E}\left(\mathbf{P}_{\mathbf{1}}\right)}{\mathbf{1}+\mathbf{k}}
$$

$\mathrm{E}\left(\mathrm{D}_{1}\right)$ - the expected dividend in cash;

$\mathrm{E}\left(\mathrm{P}_{1}\right)$ - the expected share price at the end of the period.

The required return rate is in fact a discounted rate set by the market consensus to reduce expected future cash flows to the present value and, as such, are called market capitalization rates.

2) The dividend discounting model (DDM) is the most common discount rate for stock valuation. This model implies that the company's internal value is equal to the present value of collecting all future expected dividends. To simplify it, $\mathrm{E}\left(\mathrm{D}_{1}\right)$ will be defined $\mathrm{asD}_{1}$, and $\mathrm{E}\left(\mathrm{P}_{1}\right)$ as $\mathrm{P}_{1}$. From the previous text we saw that:

$$
\mathbf{I}_{\mathbf{0}}=\frac{\mathbf{E}_{\mathbf{1}}+\mathbf{P}_{\mathbf{1}}}{\mathbf{1}+\mathbf{k}} \text { analogous to this, } \mathbf{I}_{\mathbf{1}} \text { will be } \mathbf{I}_{\mathbf{1}}=\frac{\mathbf{D}_{\mathbf{2}}+\mathbf{P}_{\mathbf{2}}}{\mathbf{1}+\mathbf{k}}
$$

If we assume that $\mathbf{P}_{\mathbf{1}}=\mathbf{I}_{\mathbf{1}}$ and term $\mathbf{I}_{\mathbf{1}}$ replace it instead of $\mathbf{P}_{\mathbf{1}}$ and then assume that the same will apply to an infinite number of consecutive periods, by further fixing we get the following expression:

$$
I_{0}=\frac{D_{1}}{1+k}+\frac{D_{2}}{(1+k)^{2}}+\frac{D_{3}}{(1+k)^{3}}+\cdots
$$

From which we conclude that the domestic value (share price) should be equal to the present value of all future dividends expected in infinity. Ordinary shares are securities without any exact life expectancy, which makes it very difficult to predict future expected dividends and it is necessary to introduce an additional variable, which is the dividend growth rate. Then assume that the amount of dividend at point 2 is equal to the amount of dividend at point 1 , corrected for the dividend increase rate $(\mathrm{g})$, on the basis of which we have:

$\mathbf{D}_{\mathbf{2}}=\boldsymbol{D}_{\mathbf{1}}\left(\mathbf{1}+\mathrm{g}_{\mathbf{2}}\right)$, from where it is: $\mathbf{g}_{\mathbf{2}}=\frac{\boldsymbol{D}_{\mathbf{2}}-\boldsymbol{D}_{\mathbf{1}}}{\boldsymbol{D}_{\mathbf{1}}}$

After the introduction of this variable, the dividend discount model can be presented in three forms:

- Model with zero growth rate of dividends, when $\mathbf{g}=\mathbf{0}$.

- Model with constant growth rate of dividend, when $\mathbf{g}=$ const.

- Model with a variable rate of dividend growth, wheng $\mathbf{g}_{1} \neq \mathbf{g}_{2}$

3) Another way of determining the value of the share is the application of the cash flow discount method. In the first variant, the discount of the Free Cash Flow for the Firm (FCFF) is carried out at the weighted average cost rate to obtain the value of the company. Then, this value decreases with the value of the debt to get the share capital. The free cash flow for a company can be determined using the following formula:

FCFF = EBIT $(1-t)+$ Am - CC -Increse of NWC 
Where:

\author{
$\boldsymbol{E B I T}$ (earnings before interest and tax); \\ $\boldsymbol{t}(\operatorname{tax})$ \\ Am (amortization); \\ CC (capital costs); \\ NWC (net working capital)
}

Another variant of this model involves the application of Free Cash Flow to Equity holders (FCFE). This flux, available to shareholders, is obtained by correcting FCFF in the following way:FCFE = FCFF - interest costs $(1-t)+$ net debt growth.

If we want to determine the final value (terminal) and assume that we have a continuous growth model, we get the following formulas if we apply cash flows FCFF and FCFE:

$$
\mathrm{P}_{\mathrm{T}}=\frac{F C F F_{T+1}}{W A C C-g} \quad \text { dhe } \quad \mathrm{P}_{\mathrm{T}}=\frac{\mathrm{FCFE}_{\mathrm{T}+1}}{\mathrm{k}_{\mathrm{E}}-\mathrm{g}}
$$

Where:

WACC (Weighted Average Cost of Capital)

$\mathrm{kE}$ - share capital cost rate.

\title{
2. 2. Methods for determining future stock price movements: basic and technical analysis
}

The current price, according to which the stock will be currently sold in the market, may be significantly different from the previously mentioned nominal value. In order for an investor to make a rational and accurate decision about what stock will be purchased, first and then at that point, an appropriate analysis is needed. An investor analysis should provide the necessary information, first of all if an action is overstated or underestimated, and then in the upcoming movement of some prices. In this regard, two important analyzes were conducted on economic theory: technical and fundamental analysis.

\subsection{Fundamental analysis}

Within a fundamental analysis, the main purpose is to identify the difference between the value and the price of an asset so that the investor succeeds in gaining market share and profit. In doing so, shares may be underestimated when their value is greater than the market price or overestimated when the market price is higher than their present value. The main idea under this analysis is the observation, "all the underlying factors that may affect the share price, such as income, sales, return on equity and the company's cash flow, which are analyzed." The two main approaches to fundamental analysis are top-down and bottom-up approaches.

If we apply the top-down approach, we will first see the price movement in the economy as a whole, then the specific sector in which the issuer belongs, then the issuer's activity and eventually within the designated company. Rather, bottom-up approaches really start from the price movement at the company level, and then macroeconomic factors or trends in the economy as a whole are gradually emerging. 
Therefore, the fundamental analysis is based on the analysis of the company's historical performance trends and expectations of future developments, mainly profits, product quality, competition, conditions in a particular industry, followed by a balance and forecast analysis of the cash flow. This analysis starts mainly from the core group of financial statements for the purpose of obtaining data on the profitability, debt and cash flows realized in the given company.

According to a fundamental analysis, the factors that influence the stock price move are numerous and can be stimulated by the company itself, or its wider and narrower environment. Some of the most important external factors are macroeconomic factors, such as the inflation rate, the gross domestic product production rate, and the amount of public debt. Other significant external factors that may affect the stock price are: trends in a particular industrial branch where the company is concerned, interest rates and exchange rate of the country in which the company operates, return rates of the equity instruments other financial assets, such as bonds and the like. Internal factors will naturally depend on the company's own performance and will be identified on the basis of the analysis of the financial statements and then the relevant statements, which will be more accurate from now on.

\section{2. 2. Technical analysis}

Technical analysis is a method by which market trends and statistical data are used to predict future stock movement and "giving an answer to a question" when "buy or sell a certain share". The essence of the technical analysis is "anticipating changes and future price levels based on historical time series and turnover volume". For this reason, technical analysis is mainly based on the use of tables, charts and coefficients, while the main driver of this analysis is the short-term, long-term forecasts of the price movement of a given stock.

Technical analysis supporters believe that the share price at a given moment will approach their fundamental (real) value, but changes in factors that affect the underlying value can be predicted in advance and that investors can use these observed price trends earlier to achieve a certain profit.

Such an understanding of technical analysts is at odds with the expectations of the functioning of an efficient capital market. According to the hypothesis of market efficiency, change in the underlying factors should immediately affect stock prices, however, technical analysts believe that this will not happen, but prices will gradually change, which will result in emerging trends in prices. Then, as mentioned, some of these trends can be used. However, if investors discover these models and try to comply with them in order to benefit, their activities will inevitably affect prices, which will result in a change in the initially-priced models. Therefore, this phenomenon is called a self-destructive model.

\section{2. 3. Dow's theory}

We have emphasized that technical analysis is mainly based on the application of charts, so technical analysts are often called Charterers. Charters use the observed trends to earn some 
profits. Dow's theory was named after its creator, Charles Dow, the founder of the Wall Street Journal, and it represents the main basis of technical analysis. The main rule of Dau's theory is that the shares are sold at the top of the downward trend and are buying at the foot of the growing trend.

The two main indicators used in Dow's theory are:

1. DJIA - Dow Jones Industrial Average and

2. DJTA - Dow Jones Transportation Average.

These two indicators are mentioned and explained above, but it is important to note that the main indicator of key trends is the DJIA index, while the DJTA index is used to control to reject or accept a particular signal provided by the market.

There are three main trends affecting stock price within Dow's theory:

1) Primary trend: may be bullish or bearish and lasts from several months to several years. This trend can not be manipulated.

In the picture 1. the bullish and bearish trends are presented with three main phases of the bullish trend (accumulation phase, public participation phase and optimism phase) and the three main phases of the bearish trend (distribution phase, public participation phase, and panic phase phases).

Fig.1.The Dow Theory Bull \& Bear Market

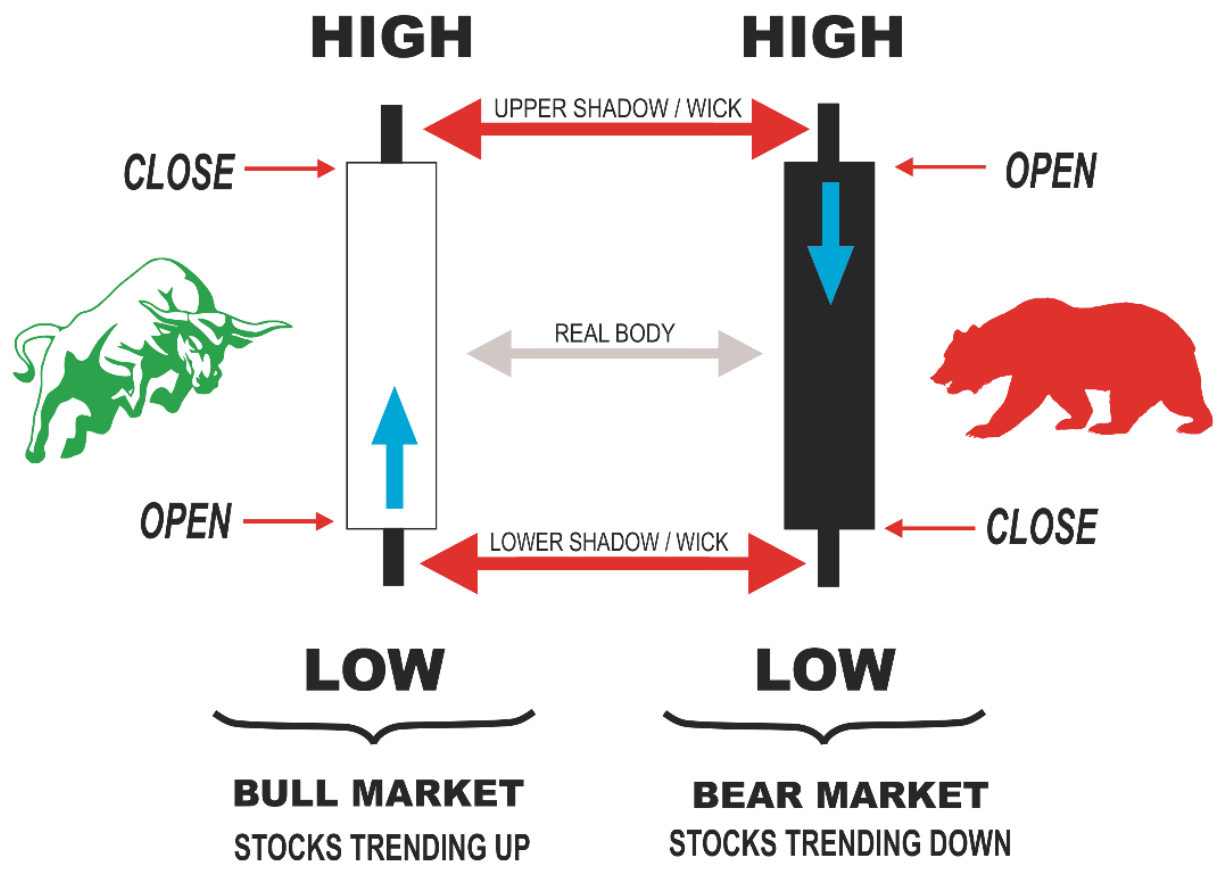

Source:http://elitemarkets.com/index.php/stocks/stock-market 
2) Secondary or secondary trend: is created due to price deviation from a basic (primary) tendency. These deviations usually last from one to three months, after which they are again approaching the main trend of price correction.

3) Tertiary or Minor Trend (Small Trend): means daily price fluctuations, which will not have a significant impact. They can last up to several weeks.

Within the framework of Daw's theory, it is important to distinguish two concepts, which are:

1) Level of support: Indicates the price level below which it can not fall action or stock index.

2) Resistance Level: indicates the level of price over which the stock is unlikely to increase or the stock index will not fall.

These two levels are determined by analyzing data on price movements in the previous period.

\section{CONCLUSION}

Investors need to understand and use different techniques, such as fundamental and technical analysis, analysis of reports and financial statements, horizontal and vertical analysis, and financial analysis from investors' point of view, which in addition to information from the basic financial reports are used market information. All of these concepts and methods are needed to get a complete picture of a company's performance so that factors affecting a business are included, measured and reported, and therefore also in the formation and movement of stock prices when it comes to joint stock companies. In the paper, we have focused on the formation of stock prices as a subject of the strong impact of a large number of different factors, which makes the prediction of their upcoming movement difficult and complex. Exactly, the stock price forecast is very difficult due to the impact of internal and external factors on a company's business and because of the difficult involvement and accurate measurement of the effects of these factors.

\section{REFERENCES}

1. Bal'azsTorma, Fundamental and technical analysis of financial markets, PhD Thesis, Computer and Automation Research Institute, Hungarian Academy of Sciences, Budapest, Hungary, 2010

2. Benjamin Graham(Author), Jason Zweig(Author), Warren E. Buffett(Collaborator), The Intelligent Investor: The Definitive Book on Value Investing. A Book of Practical Counsel (Revised Edition) (Collins Business Essentials)Paperback- February 21, 2006 
3. Benjamin Graham, David Dodd, Warren Buffett, Security Analysis: Sixth Edition, McGraw-Hill Education; 6 edition, 2008)

4. Essays of Warren-Buffett, Lessons-for-Corporate, Lawrence A. Cunningham, 1998

5. Frederic S. Mishkin\& Stanley G. Eakins, Financial Markets and Institutions SEVENTH EDITION, Prentice Hall 2012

6. Guide To Fundamental \& Technical Analysis, Rich Dad Education, 2010

7. JOHN J. MURPHY, FINANCIAL MARKETS, A COMPREHENSIVE GUIDE TO TRADING METHODS AND APPLICATIONS, NEW YORK INSTITUTE OF FINANCE, 1999

8. Martin J. Pring, Study Guide for Technical Analysis Explained, 5ed, by McGraw-Hill, 2014

9. Paul J. Mladjenovic, Stock Investing For Dummies (Business \& Personal Finance) Kindle Edition, 2016

10. Philip Fisher, Common-Stocks-and-Uncommon-Profits, Willey, 2003

11. Robert D. Edwards and John Magee, Technical Analysis of Stock, $8^{\text {th }}$. Ed. CRC Press LLC, 2001

12. RobertG. Hagstrom, The Warren Buffett Way, Wiley, 2013

13. S M Rambhia, Stock Market Investing for Beginners: Fundamental Analysis: Learn Fundamental Analysis Basics for Stocks Investing (Investing books for Beginners) (Volume 2), 2015

14. SeadinXhaferi\&Denis Spahija, MUNICIPAL BONDS AS A FINANCING FORM IN MACEDONIA, International Scientific Journal in Economics Finance, Business, Marketing, Management and Tourism, Tetovo, 2016

15. SeadinXhaferi, Financandërkombëtare, Offset, 2013

16. Seadin Xhaferi, Luljeta Sadiku, Murat Sadiku, Models for Credit Risk Assessment with regard to the Financial Market of Macedonia, QUALITY 2011, Neum, Bosnia and Herzegovina, 2011 